\title{
Mucoactive therapy in COPD
}

\author{
M. Decramer and W. Janssens
}

ABSTRACT: It has been shown that mucus hypersecretion is associated with greater susceptibility for chronic obstructive pulmonary disease (COPD), excess forced expiratory volume in $1 \mathrm{~s}$ decline, hospitalisations and excess mortality. The effects of mucoactive drugs on outcomes have been reviewed in several meta-analyses, the largest one including 26 studies. 21 studies were performed in patients with chronic bronchitis and five in patients with COPD. The majority of these trials were performed with $N$-acetylcysteine $(n=13)$ and carbocysteine $(n=3)$.

Overall, there was a significant reduction in exacerbations ( 0.05 per patient per month) and the number of days with disability ( 0.56 days per patient per month). Mucolytics were well tolerated and the number of adverse events was lower than with placebo (odds ratio 0.78 ). In the largest and best designed study with $\mathrm{N}$-acetylcysteine in 523 patients with COPD, the reduction in exacerbations was only observed in patients not taking inhaled corticosteroids. In addition, a $374 \mathrm{~mL}$ reduction in functional residual capacity was found. A recent large study $(\mathrm{n}=709)$ with high-dose carbocysteine $\left(1,500 \mathrm{mg} \cdot \mathrm{day}^{-1}\right)$ demonstrated a significant effect on exacerbations (25\% reduction) and also reported an improvement in health-related quality of life (-4.06 units in St George's Respiratory Questionnaire).

It is unclear what the mechanisms underlying these effects may be and which phenotypes benefit from this treatment. On the basis of this evidence mucoactive drugs may deserve consideration in the long-term treatment of COPD.

KEYWORDS: $\mathbf{N}$-Acetylcysteine, antioxidants, carbocysteine, chronic bronchitis, chronic obstructive pulmonary disease, mucolytics

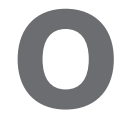
ver the years evidence has accumulated that mucus hypersecretion is an important manifestation of chronic obstructive pulmonary disease (COPD). In the classical phenotype of chronic bronchitis, mucus hypersecretion is the key presenting symptom that appears independent of airflow obstruction [1]. More recent work has demonstrated that obstruction of the small airways by inflammatory exudates containing mucus is predictive of early death after volume reduction surgery in patients with advanced COPD [2]. It was hypothesised that such occlusion enhanced the probability of infection in the lower respiratory tract. BRUSASCO et al. [3] reviewed the mechanisms of how mucus may play a role in the pathogenesis of COPD. On the basis of their review, they concluded that the data called into question the unique role of inflammation in the pathogenesis of COPD.

In addition, several epidemiological studies showed an association between mucus hypersecretion and outcomes in patients with COPD. ANNESI et al. [4] concluded that respiratory mucus hypersecretion constituted more than a negligible public health problem. SPEIZER et al. [5] showed that respiratory symptoms, after adjusting for the level of function, remained a significant predictor of mortality in COPD. VESTBO et al. [6] demonstrated that chronic mucus hypersecretion was significantly and consistently associated with both an increase in forced expiratory volume in $1 \mathrm{~s}$ (FEV1) decline and an increase of subsequent hospitalisation because of COPD. Moreover, DE MARCO et al. [7] demonstrated that the incidence of COPD in subjects who confirmed the presence of chronic cough and phlegm at the end of follow-up in their study was four-fold higher than the incidence in subjects who had never reported these symptoms. Finally, in an analysis of the Framingham offspring cohort, the presence of respiratory symptoms (including phlegm) and/or a respiratory diagnosis during followup appeared to identify a group of smokers susceptible for the development of COPD [8]. All these data supported the concept that mucus hypersecretion is not an innocent disorder.

However, despite these observations, few studies to date have focussed on the effects of mucolytic
AFFILIATIONS

Respiratory Division, University of Leuven, Leuven, Belgium.

CORRESPONDENCE

M. Decramer

University Hospital

University of Leuven

Herestraat 49

3000 Leuven

Belgium

E-mail: Marc.Decramer@

uzleuven.be

Received:

March 302010

Accepted after revision:

April 072010

PROVENANCE

Publication of this peer-reviewed article was supported by Dompé SPA, Italy (unrestricted grant,

European Respiratory Review issue 116). 
drugs in patients with COPD, even though some of these mucolytic drugs also appear to have antioxidant properties [9-11]. Indeed, there is clear evidence that COPD is also associated with increased oxidative stress [12-20]. The purpose of our study is to review the data available on the use of mucoactive (antioxidant) drugs in COPD. First, we will review the evidence available for the treatment of stable COPD and the prevention of exacerbations. Secondly, we will address the presumptive mechanisms by which potential effects of these drugs are obtained.

\section{TREATMENT OF COPD WITH MUCOLYTIC DRUGS}

A large number of studies have been performed on the use of mucolytic drugs in the treatment of chronic bronchitis and COPD. We will not distinguish between different actions of mucoactive drugs as this has already been covered in this issue of the European Respiratory Review by BALSAMO et al. [21]. The most comprehensive study, by POOLE and BLACK [22], identified 660 trials in their successive Cochrane reviews in 1997, 1999, 2006 [23] and 2010 [24]. The majority of these trials were not placebo-controlled trials in small groups of patients.

POOLE and BLACK [22] eventually identified 26 trials that were methodologically acceptable for further analysis (fig. 1). Thus, the analysis is based on slightly less than $4 \%$ of the published studies. The total number of participants was 7,335. All 26 studies were double-blind, randomised, placebo-controlled trials with a study duration ranging from 2 months to 3 yrs. 21 of the studies had a Jadad score of $>3$. The Jadad score ranges from 0 to 5 and expresses the quality of the design and the reporting of a randomised controlled trial [25]. The age of the participants ranged from 40-67 yrs and the percentage of smokers ranged from $55-100 \%$. The large majority of these studies were performed with either $N$-acetylcysteine $(n=13)$ or carbocysteine $(n=3) .21$ studies dealt with chronic bronchitis and five studies with COPD. The primary outcomes of the analysis were: 1) exacerbations; and 2) the number of days with disability. The secondary outcomes were: 1) pulmonary function; and 2) adverse events. As symptoms were not recorded in a consistent manner across the different studies, they were not used as an outcome. The number of drop-outs ranged from $0 \%$ to $38 \%$. In the study of longest duration [26], drop-out was $37 \%$ over a 3 -yr period in the placebo group. In most studies, except the former study, analysis was performed on the completer population rather than on the intention-totreat population.

The results were as follows. A statistically significant reduction in the number of exacerbations was found (0.05 exacerbations per patient per month, 95\% CI $-0.05-0.04 ; \mathrm{p}<0.01)$ (fig. 2). The reduction was greater ( 0.079 exacerbations per month) if the five COPD trials were excluded. In the largest study, no effect on exacerbations was found in the total study population [26]. There was, however, a significant reduction in the patients not taking inhaled corticosteroids (HR 0.79, 95\% CI 0.63-0.99; $p=0.04$ ). A similar result was found in another study in COPD patients who were denied inhaled corticosteroids [47]. In addition, the odds ratio for not having an exacerbation was increased with mucolytics (OR 2.13, 95\% CI 1.86-2.42; $\mathrm{p}<0.01$ ) (fig. 3). If the analysis was only performed in the trials that were conducted for $\leqslant 8$ months during the winter months, the effect was greater (OR 2.23, 95\% CI 1.95-2.56; $\mathrm{p}<0.01$ ). Finally, there was a significant reduction in the number of days with disability (0.56 days per patient per month, $95 \%$ CI $0.77-0.35$; $\mathrm{p}<0.01)$.

In addition, effects were also found on secondary outcomes. There appeared to be a small effect on FEV1 or FEV1 \% predicted $(\mathrm{p}<0.01)$. In a large 3 -yr study no effect on the rate of decline of FEV1 was found, but a $374-\mathrm{mL}$ reduction in functional residual capacity was observed $(p<0.01)$ [26]. The results on quality of life were variable with one study showing an effect [48] and another showing none [26], whereas it had not been measured in the other studies. Finally, fewer adverse events were noted with mucolytic drugs compared with placebo, largely due to the reduction in exacerbations (OR $0.78,95 \%$ CI $0.67-0.92 ; \mathrm{p}=0.002$ ).

The authors concluded that there was a significant reduction in the number of exacerbations with a mucolytic, the effect being 0.05 exacerbations per patient per month [22]. Taking into account a mean exacerbation rate of 2.6 exacerbations per year in the placebo group, this would correspond to a reduction with 0.5 exacerbations per year, or a $20 \%$ relative risk reduction. However, a significant heterogeneity was present for this effect, suggesting that caution should be taken in interpreting these data. Factors related to this heterogeneity were FEV1 \% pred, dose, duration of therapy, history of exacerbations and the use of inhaled corticosteroids. There was also a significant reduction in the number of sick days (0.56 days per patient per month). Some heterogeneity was also observed for this effect. These findings were largely in keeping with two previous reviews on the effects of $N$ acetylcysteine. A review by STEY et al. [49] included 11 randomised controlled trials and found a significant reduction in exacerbations (OR 1.56, 95\% CI 1.37-1.77) and symptoms (OR 1.78, 95\% CI 1.54-2.05). Another review, by GRANDJEAN et al. [50], confirmed the significant effect on exacerbations (OR $-1.37,95 \%$ CI $-1.5--1.25$ ).

Two recently published studies deserve special mention, particularly because of the size of their patient population

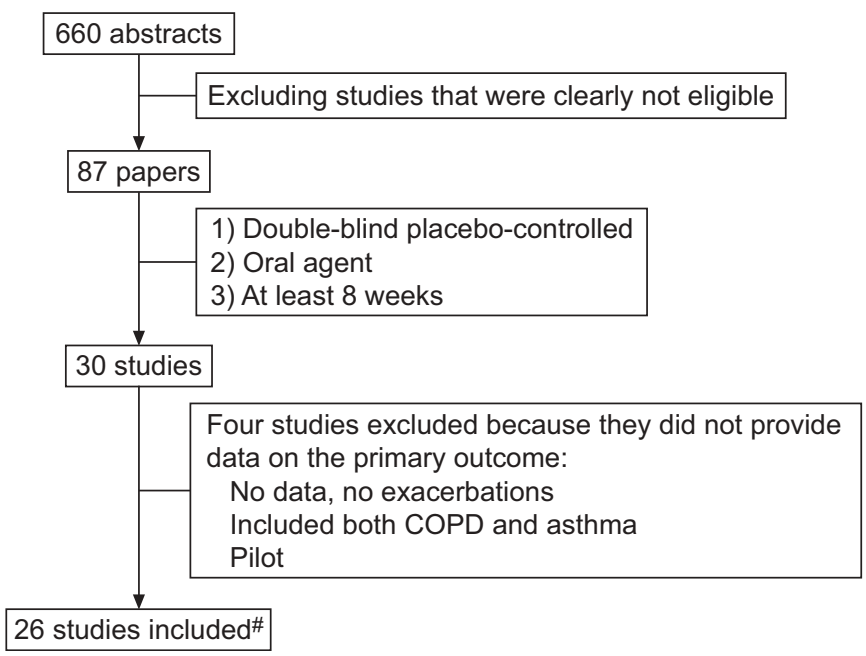

FIGURE 1. Flow chart showing of the number of studies incorporated in the Cochrane review. COPD: chronic obstructive pulmonary disease. ${ }^{\#:}<4 \%$ of the original number identified. 


\begin{tabular}{|c|c|c|c|c|c|c|c|c|c|}
\hline \multirow[t]{2}{*}{ First author [Ref.] } & \multicolumn{2}{|c|}{ Mucolytic } & \multicolumn{2}{|c|}{ Placebo } & \multirow[t]{2}{*}{ Weight \% } & \multirow{2}{*}{$\begin{array}{l}\text { Mean difference } \\
\text { IV (fixed 95\% CI) }\end{array}$} & \multirow{2}{*}{\multicolumn{2}{|c|}{$\begin{array}{l}\text { Mean difference } \\
\text { IV (fixed 95\% Cl) }\end{array}$}} & \\
\hline & Mean \pm SD & Total & Mean \pm SD & Total & & & & & \\
\hline GRASSI [27] & $0.14 \pm 0.15$ & 35 & $0.27 \pm 0.21$ & 34 & 1.1 & $-0.13(-0.22--0.04)$ & - & & \\
\hline BABOLINI [28] & $0.13 \pm 0.18$ & 254 & $0.33 \pm 0.27$ & 241 & 4.8 & $-0.20(-0.24--0.16)$ & $=$ & & \\
\hline BOMAN [30] & $0.2 \pm 0.27$ & 98 & $0.32 \pm 0.3$ & 105 & 1.3 & $-0.12(-0.20--0.04)$ & $\rightarrow$ & & \\
\hline JACKSON [31] & $0.11 \pm 0$ & 61 & $0.13 \pm 0$ & 60 & & Not estimable & & & \\
\hline MEISTER [34] & $0.15 \pm 0.15$ & 90 & $0.2 \pm 0.19$ & 91 & 3.2 & $-0.05(-0.10--0.00)$ & $=$ & & \\
\hline CREMONINI [35] & $0.25 \pm 0.23$ & 21 & $0.71 \pm 0.29$ & 20 & 0.3 & $-0.46(-0.62--0.30)$ & $\rightarrow-$ & & \\
\hline CASTIGLIONI [36] & $0.1 \pm 0.21$ & 311 & $0.2 \pm 0.29$ & 302 & 4.9 & $-0.10(-0.14--0.06)$ & $=$ & & \\
\hline OLIVIERI [37] & $0.18 \pm 0.31$ & 110 & $0.33 \pm 0.41$ & 104 & 0.8 & $-0.15(-0.25--0.05)$ & $\rightarrow-$ & & \\
\hline PARR [38] & $0.18 \pm 0.21$ & 243 & $0.21 \pm 0.21$ & 210 & 5.2 & $-0.03(-0.07-0.01)$ & $=$ & & \\
\hline RASMUSSEN [39] & $0.13 \pm 0.21$ & 44 & $0.14 \pm 0.19$ & 47 & 1.2 & $-0.01(-0.09-0.07)$ & - & & \\
\hline AlLLegRA [43] & $0.07 \pm 0.11$ & 223 & $0.11 \pm 0.14$ & 218 & 14.2 & $-0.04(-0.06--0.02)$ & - & & \\
\hline NOWAK [44] & $0.03 \pm 0.06$ & 147 & $0.06 \pm 0.12$ & 148 & 16.8 & $-0.03(-0.05--0.01)$ & 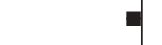 & & \\
\hline PeLA [45] & $0.17 \pm 0.18$ & 83 & $0.29 \pm 0.32$ & 80 & 1.2 & $-0.12(-0.20--0.04)$ & $\rightarrow$ & & \\
\hline MEISTER [46] & $0.06 \pm 0.15$ & 122 & $0.1 \pm 0.15$ & 124 & 5.6 & $-0.04(-0.08--0.00)$ & $=$ & & \\
\hline MALERBA [47] & $0.06 \pm 0.08$ & 115 & $0.07 \pm 0.08$ & 119 & 18.7 & $-0.01(-0.03-0.01)$ & 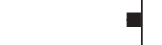 & & \\
\hline MORETTI [48] & $0.12 \pm 0.14$ & 63 & $0.17 \pm 0.17$ & 61 & 2.6 & $-0.05(-0.10-0.00)$ & $=$ & & \\
\hline DECRAMER [26] & $0.1 \pm 0.11$ & 256 & $0.11 \pm 0.16$ & 267 & 14.3 & $-0.01(-0.03-0.01)$ & 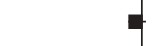 & & \\
\hline \multirow[t]{3}{*}{ Total $(95 \% \mathrm{Cl})$} & & 2543 & & 2512 & 100.0 & $-0.05(-0.05--0.04)$ & $\bullet$ & & \\
\hline & & & & & & & -0.5 & 0.5 & 1 \\
\hline & & & & & & & hucolytic & avou & cebo \\
\hline
\end{tabular}

FIGURE 2. Forest plot comparison of mucolytics versus placebo for the number of exacerbations per patient per month. Heterogenetity: Chi-squared 138.08; degrees of freedom 20 ( $p<0.00001) ; I^{2} 96 \%$. Test for overall effect: $z$-score 10.06 ( $\left.p<0.000001\right)$. IV: linear instrumental variable regression. Reproduced from [23] with permission from the publisher

and rigorous design. The first is the so-called BRONCUS study (Bronchitis Randomized on NAC Cost-Utility Study), which was published in 2005 [26]. This double-blind, placebocontrolled, randomised study included 523 patients who were followed for 3 yrs to examine the effects of $N$-acetylcysteine $600 \mathrm{mg} \cdot$ day $^{-1}$ compared to placebo. On average, patients had moderate COPD with an FEV1 of $57 \pm 9 \%$ pred with the inclusion criterion of presence of at least two exacerbations in the year preceding the study. The patients were followed for 3 yrs and were also stratified for the use of inhaled corticosteroids. The drop-out rate was $27 \%$ in the $N$-acetylcysteine group and $37 \%$ in the placebo group $(p=0.018)$. The primary end-points were rate of decline of FEV1 and exacerbations. Rate of decline of FEV1 was unaffected by treatment $\left(54 \mathrm{~mL} \cdot \mathrm{yr}^{-1}\right.$ versus $47 \mathrm{~mL} \cdot \mathrm{yr}^{-1}$ in $N$-acetylcysteine and placebo, respectively). $N$-acetylcysteine also did not affect exacerbation rate (risk ratio $0.99,95 \%$ CI $0.89-1.10$ ), but it did reduce exacerbations in the subgroup of patients not taking inhaled corticosteroids (risk ratio 0.79, 95\% CI 0.63-0.99).

Secondary end-points were health-related quality of life and cost-utility. Treatment did not affect health-related quality of life either measured with the St George's Respiratory Questionnaire or the Euro-QOL. Unexpectedly, a significant reduction in functional residual capacity $(374 \mathrm{~mL} ; \mathrm{p}<0.001)$ was observed in the $\mathrm{N}$-acetylcysteine group, indicating that $\mathrm{N}$ acetylcysteine might reduce hyperinflation in COPD patients. Such an effect was recently confirmed during exercise in a smaller study [51].

The negative results in this trial could be explained by a number of reasons. First, patients with moderate COPD were studied, whereas the effects might have been more pronounced in patients with severe COPD, as was observed with inhaled corticosteroids [52]. Secondly, although the dose studied was, at that time, the recommended dose, an effect might have been observed with a higher dose, e.g. $600 \mathrm{mg}$ three times daily. Indeed, such doses were well tolerated and produced effects on pulmonary function and diffusing capacity in patients with idiopathic pulmonary fibrosis [53]. In addition, a clear effect was observed with a higher dose of carbocysteine. Thirdly, patients with FEV1 reversibility with salbutamol were excluded, which likely introduced a bias against an effect. Finally, since the use of inhaled corticosteroids appeared to modulate the effect, the fact that $70 \%$ of the patients were on inhaled steroids might have minimised potential effects.

The second study that deserves a separate mention is the recent publication by ZHENG et al. [54], which is the PEACE Study. This double-blind, placebo-controlled trial included 709 


\begin{tabular}{|c|c|c|c|c|c|c|c|c|}
\hline \multirow[t]{2}{*}{ First author [Ref.] } & \multicolumn{2}{|c|}{ Mucolytic } & \multicolumn{2}{|c|}{ Placebo } & \multirow[t]{2}{*}{ Weight \% } & \multirow[t]{2}{*}{ Peto OR (fixed 95\% Cl) } & \multirow{2}{*}{\multicolumn{2}{|c|}{ Peto OR (fixed 95\% Cl) }} \\
\hline & Events & Total & Events & Total & & & & \\
\hline AlLEGRA [43] & 111 & 171 & 89 & 181 & 9.7 & $1.90(1.24-2.89)$ & & - \\
\hline BABOLINI [28] & 134 & 254 & 58 & 241 & 13.2 & $3.34(2.33-4.79)$ & & $\rightarrow$ \\
\hline BOMAN [30] & 46 & 98 & 29 & 105 & 5.3 & $2.28(1.29-4.03)$ & & - \\
\hline BORGIA [29] & 7 & 10 & 4 & 9 & 0.5 & $2.70(0.46-15.93)$ & & \\
\hline CAstiglioni [36] & 240 & 311 & 179 & 302 & 14.9 & $2.28(1.63-3.21)$ & & $=-$ \\
\hline GRASSI [41] & 25 & 42 & 14 & 41 & 2.3 & $2.74(1.16-6.45)$ & & \\
\hline GRILLAGE [32] & 35 & 54 & 29 & 55 & 3.0 & $1.64(0.77-3.50)$ & & \\
\hline HANSEN [42] & 36 & 59 & 34 & 70 & 3.6 & $1.64(0.82-3.29)$ & & \\
\hline JACKSON [31] & 41 & 61 & 36 & 60 & 3.2 & $1.36(0.65-2.85)$ & & | \\
\hline MALERBA [47] & 64 & 115 & 63 & 119 & 6.5 & $1.11(0.67-1.86)$ & & - \\
\hline MORETTI [48] & 26 & 63 & 13 & 61 & 3.0 & $2.50(1.18-5.33)$ & & \\
\hline NoWAK [44] & 114 & 147 & 101 & 148 & 6.5 & $1.60(0.96-2.67)$ & & \\
\hline OLIVIERI [37] & 56 & 110 & 21 & 104 & 5.5 & $3.77(2.16-6.58)$ & & \\
\hline PeLA [45] & 37 & 83 & 17 & 80 & 4.1 & $2.85(1.49-5.46)$ & & \\
\hline RASMUSSEN [39] & 28 & 44 & 24 & 47 & 2.5 & $1.66(0.73-3.80)$ & & \\
\hline Total $(95 \% \mathrm{Cl})$ & & 1962 & & 1968 & 100.0 & $2.13(1.86-2.42)$ & & \\
\hline \multirow[t]{3}{*}{ Total events } & 1153 & & 820 & & & & & \\
\hline & & & & & & 0.05 & 0.2 & 1 \\
\hline & & & & & & & rs pla & Favours $\mathrm{m}$ \\
\hline
\end{tabular}

FIGURE 3. Forest plot comparison of mucolytics versus placebo for the number of patients with no exacerbations during the study period. Heterogenetity: Chi-squared 30.56; degrees of freedom 19 ( $p<0.05) ; I^{2} 38 \%$. Test for overall effect: $z$-score $11.28(p<0.00001)$. Reproduced from [23] with permission from the publisher.

patients (table 1) and evaluated treatment with carbocysteine (500 mg three times daily) over a 1-yr follow-up period. On average, patients had severe COPD with an FEV1 of $45 \%$ pred. The primary end-point was exacerbation rate and secondary end-points were quality of life, lung function and oxygen saturation. Exacerbations were significantly reduced in the carbocysteine group (1.01 versus 1.35 excerbations per patient per year, $25 \%$ reduction) (fig. 4). As shown in figure 4 , this is primarily due to a reduction in exacerbations after the first exacerbation, as there was the same probability of being exacerbation free but a lower probability of exacerbation after the first one was observed. The risk ratio was $0.75(95 \% \mathrm{CI}$ $0.62-0.92)$. No treatment interaction was observed with Global Initiative for Chronic Obstructive Lung Disease stage or use of inhaled corticosteroids. It should be noted that the percentage of study patients taking inhaled corticosteroids (17\%) was relatively low in contrast to the BRONCUS trial [26]. Quality of life was significantly improved with carbocysteine (-4.06 units in the St George's Respiratory Questionnaire; $p=0.046)$. Clear effects on quality of life were also seen in the domain scores of symptoms and activity. No significant changes in lung function or oxygen saturation were observed. No adverse events were associated with the use of carbocysteine. Thus, this study clearly showed an effect of treatment with carbocysteine on exacerbations and quality of life in patients with, on average, severe COPD. However, in terms of magnitude of the effect, it should be stressed that the study evaluated a population in which the majority of patients did not take any maintenance treatment for COPD. In addition, 25\% of the patients were lifelong nonsmokers unlike in the other studies which were strictly confined to smokers. Finally, two other studies confirmed the reduction in exacerbations in COPD patients with carbocysteine $1,500 \mathrm{mg} \cdot \mathrm{day}^{-1}$. In the first study of 156 patients a risk ratio of $0.3(95 \%$ CI $0.2-0.7)$ was reported and in the second study of 142 patients a risk ratio of $0.37(95 \%$ CI 0.22-0.62) was observed $[55,56]$.

\section{PRESUMPTIVE MECHANISMS OF ACTION}

The studies documented above clearly demonstrate that treatment with mucoactive drugs reduces exacerbations in patients with COPD with virtually no side-effects, though the mechanisms by which these effects might be observed are still unclear. Originally, effects on mucous viscosity [57] and mucociliary clearance were declared [58, 59]. Although the compounds were originally marketed as mucolytic agents, an effect on mucociliary clearance or mucus impaction in the small airways has never been fully demonstrated. This may be related to the difficulty of measuring mucociliary transport in a reliable way [60].

A number of observations on both $N$-acetylcysteine and carbocysteine suggest that these drugs not only exert mucociliary properties but also act as antioxidant agents [61-63]. 


\begin{tabular}{|c|c|c|c|}
\hline \multirow[t]{2}{*}{ TABLE 1} & \multicolumn{3}{|c|}{$\begin{array}{l}\text { Patient demographics and baseline } \\
\text { characteristics }\end{array}$} \\
\hline & & Carbocysteine & Placebo \\
\hline \multicolumn{2}{|l|}{ Subjects } & 353 & 354 \\
\hline \multicolumn{2}{|l|}{ Males } & $273(77)$ & $282(80)$ \\
\hline \multicolumn{2}{|l|}{ Age yrs } & $65 \pm 9$ & $65 \pm 9$ \\
\hline \multicolumn{2}{|c|}{ Duration of COPD yrs } & $9 \pm 9$ & $10 \pm 9$ \\
\hline \multicolumn{4}{|c|}{ Baseline spirometry } \\
\hline \multicolumn{2}{|l|}{ FEV $1 \mathrm{~L}$} & $1.07 \pm 0.41$ & $1.12 \pm 0.43$ \\
\hline \multicolumn{2}{|c|}{ FEV $1 \%$ pred } & $44 \pm 15$ & $45 \pm 15$ \\
\hline \multicolumn{2}{|l|}{ FVC L } & $2.20 \pm 0.74$ & $2.28 \pm 0.75$ \\
\hline \multicolumn{2}{|c|}{$\mathrm{FEV}_{1} / \mathrm{FVC} \%$} & $50 \pm 13$ & $50 \pm 13$ \\
\hline \multicolumn{4}{|c|}{ GOLD stages } \\
\hline \multicolumn{2}{|c|}{ ॥ } & $167(47)$ & $177(50)$ \\
\hline \multicolumn{2}{|l|}{ III } & $139(39)$ & $140(40)$ \\
\hline \multicolumn{2}{|l|}{ IV } & $47(13)$ & $37(11)$ \\
\hline \multicolumn{2}{|c|}{ SGRQ total score } & $42 \pm 19$ & $43 \pm 19$ \\
\hline \multicolumn{4}{|c|}{ Medications for COPD prior to study } \\
\hline \multicolumn{2}{|l|}{$\beta_{2}$-agonist } & $76(22)$ & $61(17)$ \\
\hline \multicolumn{2}{|c|}{ Anticholinergic agents } & $40(11)$ & $36(10)$ \\
\hline \multicolumn{2}{|c|}{ Inhaled corticosteroids } & $64(18)$ & $54(15)$ \\
\hline \multicolumn{2}{|l|}{ Xanthines } & $113(30)$ & $95(27)$ \\
\hline
\end{tabular}

Data are presented as $n, n(\%)$ or mean \pm SD. COPD: chronic obstructive pulmonary disease; FEV1: forced expiratory volume in $1 \mathrm{~s}$; $\%$ pred: \% predicted; FVC: forced vital capacity; GOLD: Global Initiative for Chronic Obstructive Lung Disease; SGRQ: St George's Respiratory Questionnaire. Reproduced from [54] with permission from the publisher

There is accumulating evidence that oxidative stress may play an important role in the pathogenesis of COPD. This is supported by enhanced exhalation of hydrogen peroxide [13], nitric oxide [16], ethane [17], carbon monoxide [16] and isoprostane [12, 15], increased concentrations of 4-hydroxyl-2nonenal in the lungs [19] or by increased urinary excretion of isoprostane [18]. Oxidative stress causes a number of secondary

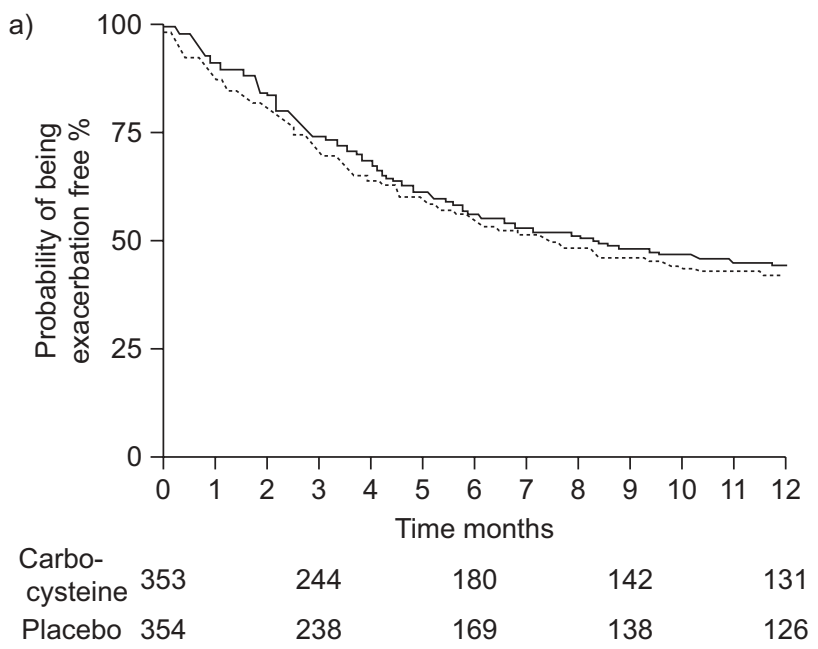

effects, such as inactivation of anti-proteases, activation of proteases, and expression of interleukin- 8 and tumour necrosis factor- $\alpha$, through expression of nuclear factor $-\kappa B$, further enhancing recruitment of neutrophils and formation of isoprostane from the oxidation of arachidonic acid [12, 15].

Other effects that were demonstrated include: 1) inhibition of epithelial thickening and secretory cell hyperplasia induced by cigarette smoke in rats [64]; 2) reduction of neutrophil and monocyte chemotaxis and oxidative burst responses in vitro $[65,66] ; 3)$ reductions of lysozyme and lactoferrin concentrations in smokers [67]; 4) reduction in the activation and number of neutrophils and macrophages in bronchoalveolar lavage fluid in smokers [68, 69]; and 5) inhibition of the adherence of bacteria to ciliated epithelial cells in vitro [70-72].

In view of these properties, $N$-acetylcysteine has not only been the subject of several controlled trials in stable COPD but has also been evaluated during acute exacerbations of COPD, which are typically accompanied by bursts of oxidative stress and inflammation [61,73]. To date, patients receiving $N$ acetylcysteine in conjunction with standard therapy for acute exacerbations had more reduced inflammatory markers, improved bacterial eradication and better subjective outcomes when compared with placebo. However, no statistically significant difference in length of hospitalisation or change of FEV1 could be observed, a finding which might be explained by the low patient number and the lack of statistical power in these studies. Overall, although antioxidants such as $N$ acetylcysteine may reduce oxidative stress in patients with COPD and during exacerbations [9-11], this is presently not demonstrated nor is the consequence of such an effect in terms of outcomes in COPD clearly established.

\section{CONCLUSIONS}

Accumulating evidence suggests that mucolytic drugs reduce exacerbations, reduce the number of sick days, reduce hyperinflation and, perhaps, improve quality of life in patients with COPD. A number of unknowns remain, particularly concerning the dose at which these effects may appear, the

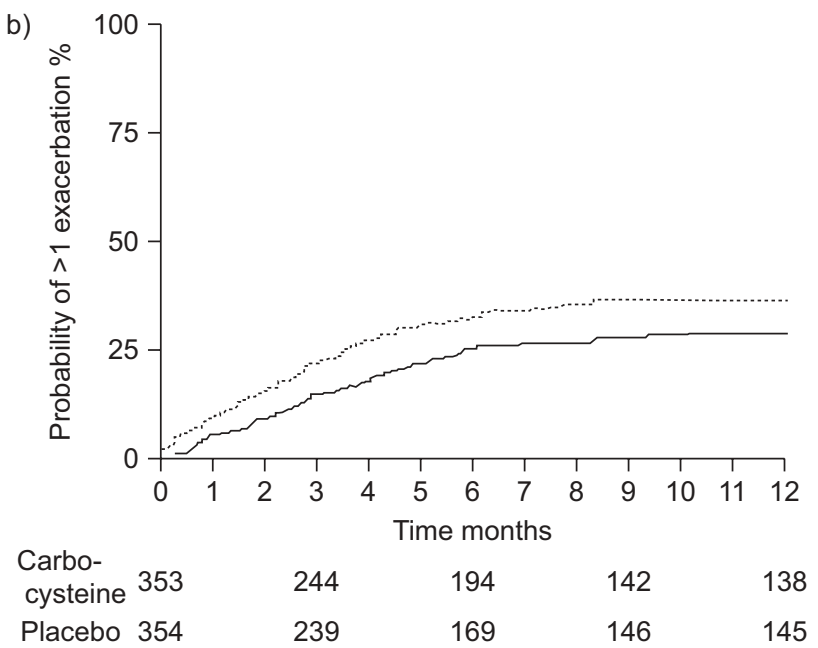

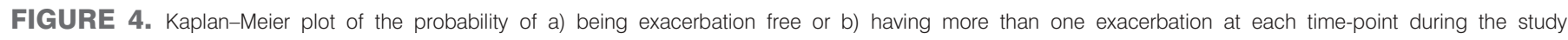
_- carbocysteine; - - - - placebo. Reproduced from [53] with permission from the publisher. 
required duration of treatment, the interaction with Global Initiative for Chronic Obstructive Lung Disease stages and the potential effects on other outcomes in COPD. More studies are needed to determine which COPD patients respond to this treatment and how this treatment interacts with other treatments before these drugs can be incorporated into the standard treatment regimens for these patients.

\section{STATEMENT OF INTEREST}

M. Decramer has been part of an advisory board for Boehringer-Pfizer GlaxoSmithKline, Nycomed and Altana. He has performed consulting work for Boehringer-Pfizer and GlaxoSmithKline. He also received lecture fees from these companies. All of the above amounted to less than $€ 10,000$ per annum. He received a research grant of $€ 45,000$ per year from AstraZeneca.

\section{REFERENCES}

1 Fletcher CM, Jones NL, Burrows B, et al. American emphysema and British bronchitis. A standardized comparative study. Am Rev Respir Dis 1964; 90: 1-13.

2 Hogg JC, Chu FS, Tan WC, et al. Survival after lung volume reduction in chronic obstructive pulmonary disease: insights from small airway pathology. Am J Respir Crit Care Med 2007; 176: 454-459.

3 Brusasco V, Crimi E, Pellegrino R. Airway inflammation in COPD friend or foe? Am J Respir Crit Care Med 2007; 176: 425-426.

4 Annesi I, Kauffmann F. Is respiratory mucus hypersecretion really an innocent disorder? A 22-year mortality survey of 1,061 working men. Am Rev Respir Dis 1986; 134: 688-693.

5 Speizer FE, Fay ME, Dockery DW, et al. Chronic obstructive pulmonary disease mortality in six U.S. cities. Am Rev Respir Dis 1989; 140: S49-S55.

6 Vestbo J, Prescott E, Lange P. Association of chronic mucus hypersecretion with FEV1 decline and chronic obstructive pulmonary disease morbidity. Copenhagen City Heart Study Group. Am J Respir Crit Care Med 1996; 153: 1530-1535.

7 de Marco R, Accordini S, Cerveri I, et al. Incidence of chronic obstructive pulmonary disease in a cohort of young adults according to the presence of chronic cough and phlegm. Am J Respir Crit Care Med 2007; 175: 32-39.

8 Kohansal R, Martinez-Camblor P, Agusti A, et al. The natural history of chronic airflow obstruction revisited: an analysis of the Framingham offspring cohort. Am J Respir Crit Care Med 2009; 180: 3-10.

9 Dekhuijzen PN. Antioxidant properties of $N$-acetylcysteine: their relevance in relation to chronic obstructive pulmonary disease. Eur Respir J 2004; 23: 629-636.

10 Rahman I, Skwarska E, MacNee W. Attenuation of oxidant/ antioxidant imbalance during treatment of exacerbations of chronic obstructive pulmonary disease. Thorax 1997; 52: 565-568.

11 Rahman I, Kilty I. Antioxidant therapeutic targets in COPD. Curr Drug Targets 2006; 7: 707-720.

12 Biernacki WA, Kharitonov SA, Barnes PJ. Increased leukotriene B4 and 8-isoprostane in exhaled breath condensate of patients with exacerbations of COPD. Thorax 2003; 58: 294-298.

13 Dekhuijzen PN, Aben KK, Dekker I, et al. Increased exhalation of hydrogen peroxide in patients with stable and unstable chronic obstructive pulmonary disease. Am J Respir Crit Care Med 1996; 154: 813-816.

14 MacNee W, Rahman I. Oxidants and antioxidants as therapeutic targets in chronic obstructive pulmonary disease. Am J Respir Crit Care Med 1999; 160: S58-S65.

15 Montuschi P, Collins JV, Ciabattoni G, et al. Exhaled 8-isoprostane as an in vivo biomarker of lung oxidative stress in patients with COPD and healthy smokers. Am J Respir Crit Care Med 2000; 162 1175-1177.
16 Montuschi P, Kharitonov SA, Barnes PJ. Exhaled carbon monoxide and nitric oxide in COPD. Chest 2001; 120: 496-501.

17 Paredi P, Kharitonov SA, Leak D, et al. Exhaled ethane, a marker of lipid peroxidation, is elevated in chronic obstructive pulmonary disease. Am J Respir Crit Care Med 2000; 162: 369-373.

18 Pratico D, Basili S, Vieri M, et al. Chronic obstructive pulmonary disease is associated with an increase in urinary levels of isoprostane F2alpha-III, an index of oxidant stress. Am J Respir Crit Care Med 1998; 158: 1709-1714.

19 Rahman I, van Schadewijk AA, Crowther AJ, et al. 4-Hydroxy-2 nonenal, a specific lipid peroxidation product, is elevated in lungs of patients with chronic obstructive pulmonary disease. Am J Respir Crit Care Med 2002; 166: 490-495.

20 Repine JE, Bast A, Lankhorst I. Oxidative stress in chronic obstructive pulmonary disease. Oxidative Stress Study Group. Am J Respir Crit Care Med 1997; 156: 341-357.

21 Balsamo R, Lanata L, Egan CG. Mucoactive drugs. Eur Respir Rev 2010; 19: 127-133.

22 Poole PJ, Black PN. Oral mucolytic drugs for exacerbations of chronic obstructive pulmonary disease: systematic review. BMJ 2001; 322: 1271-1274.

23 Poole PJ, Black PN. Mucolytic agents for chronic bronchitis or chronic obstructive pulmonary disease. Cochrane Database Syst Rev 2006; 3: CD001287.

24 Poole P, Black PN. Mucolytic agents for chronic bronchitis or chronic obstructive pulmonary disease. Cochrane Database Syst Rev 2010; 2: CD001287.

25 Jadad AR, Moore RA, Carroll D, et al. Assessing the quality of reports of randomized clinical trials: is blinding necessary? Control Clin Trials 1996; 17: 1-12.

26 Decramer M, Rutten-van Mölken M, Dekhuijzen PN, et al. Effects of $N$-acetylcysteine on outcomes in chronic obstructive pulmonary disease (Bronchitis Randomized on NAC Cost-Utility Study, BRONCUS): a randomised placebo-controlled trial. Lancet 2005; 365: 1552-1560.

27 Grassi C, Morandini GC. A controlled trial of intermittent oral acetylcysteine in the long-term treatment of chronic bronchitis. Eur J Clin Pharmacol 1976; 9: 393-396.

28 Babolini G. Long-term oral acetylcysteine in chronic bronchitis. A double-blind controlled study. Eur J Respir Dis Suppl 1980; 31: 93-108.

29 Borgia M, Sepe N, Ori-Belometti M, et al. Confronto tra acetilcisteina e placebo nel trattamento a lungo termine della bronchite cronica. [Comparison between acetylcysteine and placebo in the long term treatment of chronic bronchitis]. Gazzetta Medica Italiana 1981; 140: 467-472.

30 Boman G, Backer U, Larsson S, et al. Oral acetylcysteine reduces exacerbation rate in chronic bronchitis; report of a trial organized by the Swedish Society for Pulmonary Diseases. Eur J Respir Dis 1983; 64: 405-415.

31 Jackson IM, Barnes J, Cooksey P. Efficacy and tolerability of oral acetylcysteine (fabrol) in chronic bronchitis: a double-blind placebo controlled trial. J Int Med Res 1984; 12: 198-206.

32 Grillage M, Barnard-Jones K. Long-term oral carbocisteine therapy in patients with chronic bronchitis. A double blind trial with placebo control. Br J Clin Prac 1985; 39: 395-398.

33 McGavin CR, Macfarlane JT, Prescott RJ, et al. Oral N-acetylcysteine and exacerbation rates in patients with chronic bronchitis and severe airways obstruction. British Thoracic Society Research Committee. Thorax 1985; 40: 832-835.

34 Meister R. Long-term therapy with acetylcysteine retard tablets in patients with chronic bronchitis: a double-blind. placebo controlled study. 1986.

35 Cremonini C, Spada E, Cellini F, et al. I farmaci attivi sul muco nel trattamento di fondo della bronchite cronica. [Pharmacotherapy which acts on mucus in long-term treatment of chronic bronchitis]. La Clinica Terapeutica 1986; 116: 121-129. 
36 Castiglioni CL, Gramolini C. Effect of long-term treatment with sobrerol on the exacerbations of chronic bronchitis. Respiration 1986; 50: 202-217.

37 Olivieri D, Zavattini G, Tomasini G, et al. Ambroxol for the prevention of chronic bronchitis exacerbations: long-term multicenter trial. Respiration 1987; 51: 42-51.

38 Parr GD, Huitson A. Oral fabrol (oral $N$-acetyl-cysteine) in chronic bronchitis. Br J Dis Chest 1987; 81: 341-348.

39 Rasmussen JB, Glennow C. Reduction in days of illness after longterm treatment with $\mathrm{N}$-acetylcysteine controlled-release tablets in patients with chronic bronchitis. Eur Respir J 1988; 1: 351-355.

40 Bontognali E. Clinical effectiveness and tolerance of cithiolone in the prophylaxis of acute infective exacerbations in patients suffering from chronic bronchitis. Acta Therapeutica 1991; 17: 155-162.

41 Grassi C, Casali L, Ciaccia A, et al. Terapia intervallare con l'associazione carbocisteina-sobrerolo nella profilassi delle riacutizzazioni della bronchite cronica. Ital J Chest Dis 1994; 48: 17-26.

42 Hansen NC, Skriver A, Brorsen-Riis L, et al. Orally administered $\mathrm{N}$-acetylcysteine may improve general well-being in patients with mild chronic bronchitis. Respir Med 1994; 88: 531-535.

43 Allegra L, Cordaro CI, Grassi C. Prevention of acute exacerbations of chronic obstructive bronchitis with carbocysteine lysine salt monohydrate: a multicenter, double-blind, placebo-controlled trial. Respiration 1996; 63: 174-180.

44 Nowak D, Carati L, Pirozynski M. Long-term administration of Nacetylcysteine reduces the number of acute exacerbation episodes in subjects with chronic obstructive pulmonary disease: report of the BREATHE study. Eur Respir J 1999; 14: Suppl. 30, 381S-382S.

45 Pela R, Calcagni AM, Subiaco S, et al. N-Acetylcysteine reduces the exacerbation rate in patients with moderate to severe COPD. Respiration 1999; 66: 495-500.

46 Meister R, Wittig T, Beuscher N, et al. Efficacy and tolerability of myrtol standardized in long-term treatment of chronic bronchitis. A double-blind, placebo-controlled study. Study Group Investigators. Arzneimittelforschung 1999; 49: 351-358.

47 Malerba M, Ponticiello A, Radaeli A, et al. Effect of twelve-months therapy with oral ambroxol in preventing exacerbations in patients with COPD. Double-blind, randomized, multicenter, placebo-controlled study (the AMETHIST Trial). Pulm Pharmacol Ther 2004; 17: 27-34.

48 Moretti M, Bottrighi P, Dallari R, et al. The effect of long-term treatment with erdosteine on chronic obstructive pulmonary disease: the EQUALIFE Study. Drugs Exp Clin Res 2004; 30: 143-152.

49 Stey C, Steurer J, Bachmann S, et al. The effect of oral Nacetylcysteine in chronic bronchitis: a quantitative systematic review. Eur Respir J 2000; 16: 253-262.

50 Grandjean EM, Berthet P, Ruffmann R, et al. Efficacy of oral longterm $N$-acetylcysteine in chronic bronchopulmonary disease: a meta-analysis of published double-blind, placebo-controlled clinical trials. Clin Ther 2000; 22: 209-221.

51 Stav D, Raz M. Effect of N-acetylcysteine on air trapping in COPD: a randomized placebo-controlled study. Chest 2009; 136: 381-386.

52 Burge PS, Calverley PM, Jones PW, et al. Randomised, double blind, placebo controlled study of fluticasone propionate in patients with moderate to severe chronic obstructive pulmonary disease: the ISOLDE trial. BMJ 2000; 320: 1297-1303.

53 Demedts $\mathrm{M}$, Behr J, Buhl R, et al. High-dose acetylcysteine in idiopathic pulmonary fibrosis. N Engl J Med 2005; 353: 2229-2242.

54 Zheng JP, Kang J, Huang SG, et al. Effect of carbocisteine on acute exacerbation of chronic obstructive pulmonary disease (PEACE Study): a randomised placebo-controlled study. Lancet 2008; 371 : 2013-2018.
55 Tatsumi K, Fukuchi Y. Carbocisteine improves quality of life in patients with chronic obstructive pulmonary disease. J Am Geriatr Soc 2007; 55: 1884-1886.

56 Yasuda H, Yamaya M, Sasaki T, et al. Carbocisteine reduces frequency of common colds and exacerbations in patients with chronic obstructive pulmonary disease. J Am Geriatr Soc 2006; 54: 378-380.

57 Houtmeyers E, Gosselink R, Gayan-Ramirez G, et al. Effects of drugs on mucus clearance. Eur Respir J 1999; 14: 452-467.

58 Sheffner AL. The reduction in vitro in viscosity of mucoprotein solutions by a new mucolytic agent, $\mathrm{N}$-acetyl-L-cysteine. Ann N Y Acad Sci 1963; 106: 298-310.

59 Colombo B, Turconi P, Daffonchio L, et al. Stimulation of C1secretion by the mucoactive drug $S$-carboxy-methylcysteinelysine salt in the isolated rabbit trachea. Eur Respir J 1994; 7: 1622-1628.

60 Olivieri D, Marsico SA, Del DM. Improvement of mucociliary transport in smokers by mucolytics. Eur J Respir Dis Suppl 1985; 139: 142-145.

61 Zuin R, Palamidese A, Negrin R, et al. High-dose N-acetylcysteine in patients with exacerbations of chronic obstructive pulmonary disease. Clin Drug Investig 2005; 25: 401-408.

62 Guizzardi F, Rodighiero S, Binelli A, et al. S-CMC-Lys-dependent stimulation of electronic glutathione secretion by human respiratory epithelium. J Mol Med 2006; 84: 97-107.

63 Garavaglia ML, Bononi E, Dossena S, et al. S-CMC-Lys-protective effects on human respiratory cells during oxidative stress. Cell Physiol Biochem 2008; 22: 455-464.

64 Rogers DF, Jeffery PK. Inhibition by oral $N$-acetylcysteine of cigarette smoke-induced "bronchitis" in the rat. Exp Lung Res 1986; 10: 267-283.

65 Kharazmi A, Nielsen H, Bendtzen K. Recombinant interleukin 1 alpha and beta prime human monocyte superoxide production but have no effect on chemotaxis and oxidative burst response of neutrophils. Immunobiology 1988; 177: 32-39.

66 Asti C, Melillo G, Caselli GF, et al. Effectiveness of carbocysteine lysine salt monohydrate on models of airway inflammation and hyperresponsiveness. Pharmacol Res 1995; 31: 387-392.

67 Linden M, Wieslander E, Eklund A, et al. Effects of oral Nacetylcysteine on cell content and macrophage function in bronchoalveolar lavage from healthy smokers. Eur Respir J 1988; 1: 645-650.

68 Eklund A, Eriksson O, Hakansson L, et al. Oral N-acetylcysteine reduces selected humoral markers of inflammatory cell activity in BAL fluid from healthy smokers: correlation to effects on cellular variables. Eur Respir J 1988; 1: 832-838.

69 Bergstrand H, Bjornson A, Eklund A, et al. Stimuli-induced superoxide radical generation in vitro by human alveolar macrophages from smokers: modulation by $\mathrm{N}$-acetylcysteine treatment in vivo. J Free Radic Biol Med 1986; 2: 119-127.

70 Niederman MS, Rafferty TD, Sasaki CT, et al. Comparison of bacterial adherence to ciliated and squamous epithelial cells obtained from the human respiratory tract. Am Rev Respir Dis 1983; 127: 85-90.

71 Yasuda H, Yamaya M, Sazaki T, et al. Carbocisteine inhibits rhinovirus infection in human tracheal epithelial cells. Eur Respir J 2006; 28: 51-58.

72 Suer E, Sayrac S, Ozturk HE, et al. Variation in attachment of Streptococcus pneumoniae to human pharyngeal epithelial cells after treatment with S-carboxymethylcysteine. J Infect Chemother 2008; 14: 333-336.

73 Reichenberger F, Tamm M. [N-acetylcystein in the therapy of chronic bronchitis]. Pneumologie 2002; 56: 793-797. 